\title{
Influence of Pre-Aging on the Artificial Aging Behavior of a 6056 Aluminum Alloy after Conventional Extrusion
}

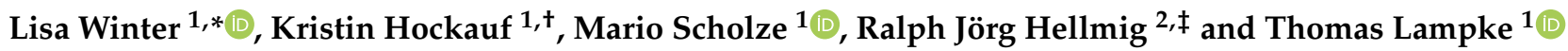 \\ 1 Institute of Materials Science and Engineering, Chemnitz University of Technology, \\ D-09125 Chemnitz, Germany; hockauf@hs-mittweida.de (K.H.); mario.scholze@mb.tu-chemnitz.de (M.S.); \\ thomas.lampke@mb.tu-chemnitz.de (T.L.) \\ 2 EJOT GmbH and Co. KG., Industrial Fasteners Division, D-57319 Bad Berleburg, Germany; \\ rhellmig@ejot.com \\ * Correspondence: lisa.winter@mb.tu-chemnitz.de \\ + Present address: Chair of Smart Materials, Department of Engineering Sciences, \\ Mittweida University of Applied Sciences, D-09648 Mittweida, Germany. \\ $\ddagger$ Present address: Institute of Materials Engineering, University of Siegen, D-57068 Siegen, Germany.
}

check for updates

Citation: Winter, L.; Hockauf, K.; Scholze, M.; Hellmig, R.J.; Lampke, T. Influence of Pre-Aging on the Artificial Aging Behavior of a 6056 Aluminum Alloy after Conventional Extrusion. Metals 2021, 11, 385. https://doi.org/10.3390/met11030385

Academic Editor: Mariusz Król

Received: 20 January 2021

Accepted: 19 February 2021

Published: 26 February 2021

Publisher's Note: MDPI stays neutral with regard to jurisdictional claims in published maps and institutional affiliations.

Copyright: (c) 2021 by the authors. Licensee MDPI, Basel, Switzerland. This article is an open access article distributed under the terms and conditions of the Creative Commons Attribution (CC BY) license (https:// creativecommons.org/licenses/by/ $4.0 /)$.

\begin{abstract}
In the present study, the influence of the initial heat-treatment conditions on the artificial aging behavior after conventional linear extrusion at room temperature was investigated for the precipitation hardening of a 6056 aluminum alloy. A solution-annealed condition was systematically compared to naturally-aged and pre-aged conditions. Differential scanning calorimetry was used for analyzing the precipitation sequence and its dependence on the initial heat treatment. The natural aging behavior prior to extrusion and the artificial aging behavior after extrusion were determined by microhardness measurements as a function of the aging time. Furthermore, the microstructure, dependent on the induced strain, was investigated using optical microscopy and transmission electron microscopy. As a result of pre-aging, following a solid-solution treatment, the formation of stable room-temperature clusters was suppressed and natural aging was inhibited. The artificial aging response after extrusion was significantly enhanced by pre-aging, and the achieved hardness and strength were significantly higher when compared with the equally processed solution-annealed or naturally-aged conditions.
\end{abstract}

Keywords: aluminum alloy; thermomechanical treatment; pre-aging; aging behavior; differential scanning calorimetry; hardness

\section{Introduction}

Aluminum alloys of the 6xxx series are of major technological importance and have been studied extensively. Because of their good formability combined with their precipitation hardening ability, they are attractive to the automotive and aircraft industries. The chemical composition of these alloys directly influences the complex precipitation sequence and thus the hardening response during aging. The primary strengthening of $\mathrm{Al}-\mathrm{Mg}-\mathrm{Si}$ alloys is attributed to the ternary needle-shaped phase $\beta^{\prime \prime}[1-4]$. With the addition of $\mathrm{Cu}$, the quaternary lath-shaped phase $Q^{\prime}$ further contributes to the strengthening $[4,5]$. These metastable phases are precursors for the stable phases of $\beta\left(\mathrm{Mg} \mathrm{Si}_{2}\right)$ and $\mathrm{Q}\left(\mathrm{Al}_{5} \mathrm{Cu}_{2} \mathrm{Mg}_{8} \mathrm{Si}_{6}\right)$, respectively [4], and the precipitation sequence is generally accepted as follows [4-8]:

At room temperature, $\mathrm{Mg}$-Si co-clusters evolve from a super-saturated solution. At higher temperatures, nanoscale precipitates with an ordered arrangement of $\mathrm{Mg}-$, $\mathrm{Si}$ - and $\mathrm{Cu}$-atoms are formed, which are referred to as Guinier-Preston (GP) zones [9].

Depending on their composition, $\mathrm{Al}-\mathrm{Mg}-\mathrm{Si}$ alloys containing $\mathrm{Cu}$ show a pronounced tendency towards natural aging, which has a detrimental effect on the further hardening response during the subsequent artificial aging $[10,11]$. The clusters of the solute $\mathrm{Mg}$ and Si atoms formed by natural aging inhibit the nucleation of the strengthening phase $\beta^{\prime \prime}$ [12]. 
In industrial production, interim storage periods between single processing steps cannot often be avoided because of cost efficient manufacturing and different production locations. Pre-aging at low artificial aging temperatures subsequent to the solid-solution treatment is a common strategy to prevent natural aging and increase room temperature stability $[13,14]$. By pre-aging, the clustering of solute atoms is suppressed and the alternatively formed GP zones enhance the nucleation of $\beta^{\prime \prime}$ and further enhance the hardening response [13].

$\alpha$ /super-saturated solution $\rightarrow$ cluster $\rightarrow$ metastable $\beta^{\prime \prime} /$ GP-zones $\rightarrow$ metastable $\beta^{\prime}+Q^{\prime} \rightarrow$ stable $\beta+Q+$ Si

Regarding the mechanical properties, for precipitation hardening aluminum alloys, an effective strategy to achieve a high strength and good ductility was developed by Kim et al. [15]. Solid-solution treatment followed by severe cold plastic deformation and artificial aging significantly increases strength through the induced strain hardening. Furthermore, the accelerated precipitation kinetics due to the induced strain lead to the rapid formation of fine precipitates during artificial aging. Simultaneously, the ductility, which is decreased by strain hardening, is regained through thermal recovery processes. The induced strain, as well as the artificial aging temperature and time, are major influencing factors on the achieved mechanical properties $[7,16]$. The best combination of strength and ductility is realized through low artificial aging temperatures with short aging times [7,17]. Despite the attractive mechanical properties that are able to be achieved, the transfer of this processing strategy into industrial manufacturing is impeded because of the costly implementation of the subsequent plastic deformation after solid-solution treatment.

Thus, the main focus of the present study was the influence of the initial heat treatments prior to cold plastic deformation followed by artificial aging on the hardening response. For the initial heat treatments, a solution-annealed condition was compared with naturally-aged and pre-aged conditions. A 6056 aluminum alloy was investigated because of its pronounced hardening during natural and artificial aging and its broad industrial application. Furthermore, conventional linear extrusion for cold plastic deformation was chosen. Artificial aging was conducted at a relatively low temperature, because of its beneficial effect on the achievable peak hardness [18], as well as to prevent over-aging and pronounced softening effects.

\section{Materials and Methods}

\subsection{Material and Heat Treatment}

For this study, the precipitation hardening of a 6056 aluminum alloy (A1Si1MgCuMn) was examined. The chemical composition and the initial mechanical properties of the aluminum wire of a commercial purity, provided by EJOT GmbH and Co. KG (Bad Berleburg, Germany), are given in Tables 1 and 2, respectively.

Table 1. Chemical composition of the 6056 aluminum alloy wire (AlSi1MgCuMn).

\begin{tabular}{|c|c|c|c|c|c|c|c|c|c|}
\hline Element Si & Mg & $\mathrm{Cu}$ & Mn & $\mathrm{Zn}$ & $\mathrm{Fe}$ & $\mathrm{Zr}$ & $\mathbf{T i}$ & $\mathrm{Cr}$ & Al \\
\hline wt. $\%$ & 0.89 & 0.78 & 0.59 & 0.19 & 0.16 & 0.13 & 0.04 & 0.01 & balance \\
\hline
\end{tabular}

Table 2. Geometrical and mechanical properties of the 6056 aluminum alloy wire in the as-received condition. The deviation is given in absolute values.

\begin{tabular}{llll}
\hline $\begin{array}{l}\text { Wire Diameter } \\
\boldsymbol{d} \text { in } \mathbf{~ m m}\end{array}$ & $\begin{array}{l}\text { Yield Strength } \\
\boldsymbol{R}_{\boldsymbol{p} \mathbf{0 . 2}} \text { in } \mathbf{M P a}\end{array}$ & $\begin{array}{l}\text { Ultimate Tensile Strength } \\
\boldsymbol{R}_{\boldsymbol{m}} \text { in } \mathbf{M P a}\end{array}$ & $\begin{array}{l}\text { Elongation } \\
\boldsymbol{A}_{\mathbf{1 0 0 m m}} \text { in \% }\end{array}$ \\
\hline 5.26 & $173 \pm 1$ & $188 \pm 2$ & $6.3 \pm 1.3$ \\
\hline
\end{tabular}

Three different initial heat-treatment conditions were compared, namely: solutionannealed, pre-aged and naturally-aged conditions. All conditions were solution annealed for $1 \mathrm{~h}$ at $530{ }^{\circ} \mathrm{C}$, and were quenched in water at room temperature. After the solid-solution 
treatment, the solution-annealed condition was directly processed. Subsequent to the solid-solution treatment, the alloy was annealed for $5 \mathrm{~h}$ at $80^{\circ} \mathrm{C}$ to obtain the pre-aged condition, or was naturally aged for $7 \mathrm{~d}$ at room temperature.

The three heat treatment conditions were linearly extruded at room temperature by EJOT GmbH and Co. KG (Bad Berleburg, Germany). Two different strains were introduced, namely $\varphi=0.8$ and $\varphi=1.2$, which were defined by the diameter reduction of the aluminum wire in the as-received condition. Strain $\varphi$ was calculated from the ratio of the wire's cross-sectional before extrusion $\left(A_{0}\right)$ and after extrusion $\left(A_{1}\right)$, as follows:

$$
\varphi=\ln \frac{A_{0}}{A_{1}}
$$

To examine the influence of the initial heat treatment and the further plastic deformation on the artificial aging behavior, the conditions investigated were artificially aged at $120^{\circ} \mathrm{C}$ for up to $10 \mathrm{~h}$ after extrusion processing.

To prevent undesired natural aging between the initial heat treatment, linear extrusion and artificial aging, the wire specimens were either produced in a continuous route or the specimens were stored at $-20{ }^{\circ} \mathrm{C}$ in a freezer between the processing steps.

\subsection{Differential Scanning Calorimetry}

The precipitation behavior of the aluminum alloy and the influence of pre-aging were studied by differential scanning calorimetry (DSC) measurements using a DSC 1 System (Mettler Toledo AG, Gießen, Switzerland). Relatively large masses are required for the investigation of precipitation kinetics in aluminum 6xxx alloys when using DSC at low heating rates [19]. Therefore, cylindrical specimens with a diameter of $5 \mathrm{~mm}$ and a height of $5 \mathrm{~mm}$ were machined from the investigated alloy. The weight of each specimen tested was approximately $256 \mathrm{mg}$. For reference, a high-purity A15N aluminum sample with a weight of $256 \mathrm{mg}$ was used. Both specimens were put into aluminum pans, the measurements were performed in a nitrogen atmosphere and the contact area between the pan and the sample was additionally polished for better thermal conductivity. The thermal cycling first contained an initial isothermal step at $10{ }^{\circ} \mathrm{C}$ for $10 \mathrm{~min}$ in order to achieve a settled condition. Subsequently, heating to $380^{\circ} \mathrm{C}$ was conducted, followed by isothermal holding for $10 \mathrm{~min}$ and cooling to $10^{\circ} \mathrm{C}$. A rerun of this complete cycle was performed for control and baseline correction. The solution-annealed and the pre-aged conditions were compared at three different heating rates $(5,10$ and $20 \mathrm{~K} / \mathrm{min})$.

\subsection{Hardness Measurement}

To study the natural aging behavior, the undeformed aluminum wires in solutionannealed and pre-aged conditions were measured using a KB250BVRZ automatic hardness tester (KB Prüftechnik GmbH, Hochdorf-Assenheim, Germany) with a microhardness of HV0.5. Samples of both initial heat-treatment conditions were subjected to natural aging for four weeks at room temperature, and the microhardness was continuously measured during this time. Furthermore, the artificial aging behaviors after linear extrusion of the solution-annealed, pre-aged and naturally-aged conditions were investigated using a DuraScan 70 G5 automatic hardness tester (EMCO-TEST Prüfmaschinen GmbH, Kuchl, Austria) with a microhardness of HV0.1. These measurements were done by EJOT GmbH and Co. KG (Bad Berleburg, Germany) directly after processing.

For all material conditions, 20 microhardness measurements were conducted on the cross sections of each of the wire specimens, from the edge to core.

\subsection{Tensile Testing}

Tensile tests were conducted in quasistatic conditions (strain rate of $10^{-3} \mathrm{~s}^{-1}$ ). The ultimate tensile strength after artificial aging, dependent on the aging time, was determined for the three initial heat-treatment conditions after linear extrusion with $\varphi=1.2$. The tensile testing was done by EJOT GmbH and Co. KG (Bad Berleburg, Germany), and the wire 
specimens for each of the heat-treatment conditions and aging times were tested using a Lloyd Instruments EZ 50 materials testing machine (Ametek GmbH, Meerbusch, Germany).

\subsection{Microstructural Characterization}

Microstructural analyses were performed on polished samples taken parallel to the extrusion direction. The influence of the induced strain by extrusion on the microstructure was analyzed through optical microscopy with an Olympus GX51 (Olympus Deutschland $\mathrm{GmbH}$, Hamburg, Germany).

To determine the influence of the initial heat-treatment conditions on the microstructure at the beginning of the artificial aging after extrusion, a transmission electron microscopy (TEM) was performed using a Hitachi H8100 microscope (Hitachi High-Tech Europe $\mathrm{GmbH}$, Krefeld, Germany) operating with an acceleration voltage of $200 \mathrm{kV}$. The samples were extracted parallel to the extrusion direction, and were electrolytically thinned and ion polished.

\section{Results}

\subsection{Precipitation Sequence}

The DSC thermograms obtained for the solution-annealed, naturally-aged and preaged conditions are shown in Figure 1. In accordance with the literature, the peaks shifted towards higher temperatures, and their height increased along with the increase in the heating rate. Hereinafter, the peak temperatures are discussed for a heating rate of $5 \mathrm{~K} \mathrm{~min}^{-1}$ (see Figure 1a). Five exothermic formation peaks occurred, and these were identified based on the literature $[4,5,11,20,21]$, as follows:

- $\quad$ peak I at $80^{\circ} \mathrm{C}$ : separate $\mathrm{Mg}$ - and Si-clusters, as well as Mg-Si co-clusters;

- $\quad$ peak II at $160^{\circ} \mathrm{C}$ : GP-zones;

- $\quad$ peak III at $230{ }^{\circ} \mathrm{C}: \beta^{\prime \prime}$-precipitates;

- $\quad$ peak IV at $270^{\circ} \mathrm{C}: \beta^{\prime}$-precipitates;

- $\quad$ peak V at $320^{\circ} \mathrm{C}$ : Q-precipitates.

The DSC curves and the temperatures of the formation peaks were similar for the solution-annealed and pre-aged conditions. However, the significant difference between these two conditions was the absence of peak I for the pre-aged condition. After pre-aging at $80{ }^{\circ} \mathrm{C}$, the formation of stable $\mathrm{Mg}$-Si co-clusters was not observed in the thermograms. Instead, the formation of GP zones in peak II was the first visible deviation from baseline. The further precipitation sequence is unchanged when compared to the solution-annealed condition. In contrast to these two material conditions, for the naturally-aged material, peak II shifted towards lower temperatures. As observed for the pre-aged condition, the formation of Mg-Si co-clusters, expressed by peak I, was absent. When comparing the solutionannealed and pre-aged conditions, the most significant difference was the pronounced endothermic peak at approximately $180-210^{\circ} \mathrm{C}$, which corresponded to the dissolution of the co-clusters $[22,23]$. Furthermore, peak III showed a higher exothermic reaction and was shifted towards higher temperatures, as a result of the natural aging time [22,24].

\subsection{Aging Behavior}

The natural aging responses for the solution-annealed and pre-aged conditions are shown in Figure 2. The hardness of the solution-annealed condition increased almost linearly with the increasing aging time, from 68 HV0.5 90 min after quenching to $91 \mathrm{HV} 0.5$ after four weeks. The pre-aged condition exhibited a significantly higher initial hardness of $80 \mathrm{HV} 0.5$. In contrast to the solution-annealed condition, the hardness remained almost constant within the first three weeks of natural aging. However, thereafter, the hardness increased similarly to the solution-annealed condition, even though it remained lower overall with 86 HV0.5 after four weeks.

In Figure 3, the artificial aging response, dependent on additional plastic deformation prior to the artificial aging, is shown for the three tested initial heat-treatment conditions. When comparing the non-extruded conditions, the highest peak hardness, 
118 HV0.1, was achieved with an initial solid-solution treatment followed by artificial aging for $300 \mathrm{~min}$ (Figure 3a). The peak hardness results of the naturally-aged and pre-aged conditions were lower, at approximately 107 HV0.1 for both. However, these hardness results were already reached after 60-120 min aging time. Linear extrusion prior to artificial aging significantly increased the hardness of all of the initial heat-treatment conditions (Figure 3b,c). Furthermore, the pre-aged condition generally exhibited a higher hardness during the entire artificial aging time when compared with the solution-annealed or naturally-aged conditions. A peak hardness of approximately $162 \mathrm{HV} 0.1$ for the pre-aged condition after extrusion was achieved after $300 \mathrm{~min}$ aging time.

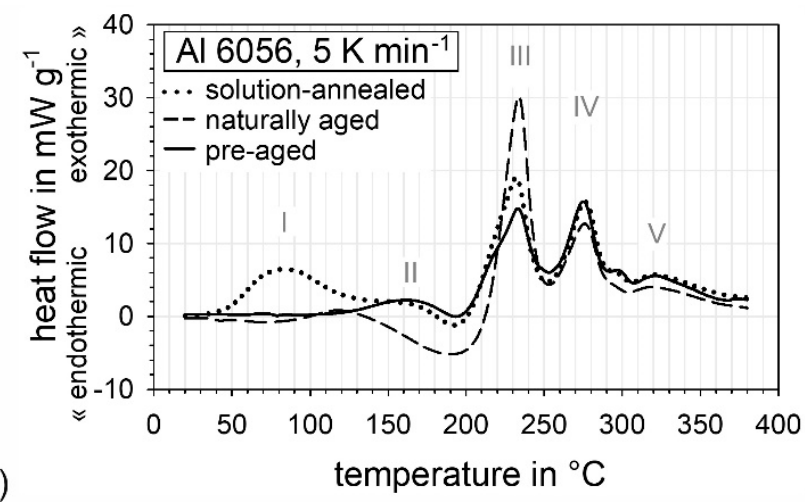

a)
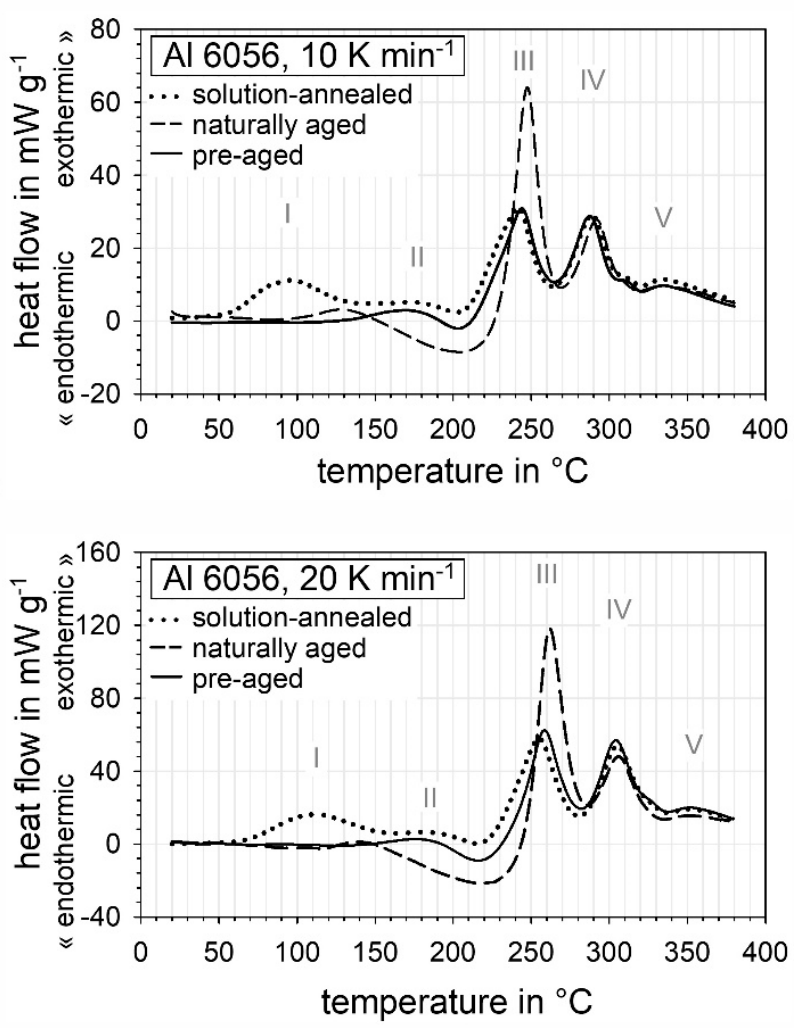

Figure 1. Differential scanning calorimetry (DSC) thermograms for the 6056 aluminum alloy in solution-annealed, naturally-aged and pre-aged conditions obtained for the following three heating rates: (a) $5 \mathrm{~K} \mathrm{~min}^{-1}$, (b) $10 \mathrm{~K} \mathrm{~min}^{-1}$ and (c) $20 \mathrm{~K} \mathrm{~min}^{-1}$. With an increased heating rate, the peaks shift towards higher temperatures. After pre-aging at $80{ }^{\circ} \mathrm{C}$, the formation of $\mathrm{Mg}$-Si co-clusters (peak I) is not observed in the thermograms. The naturally-aged condition shows a pronounced endothermic peak, which corresponds to the dissolution of the Mg-Si co-clusters. 


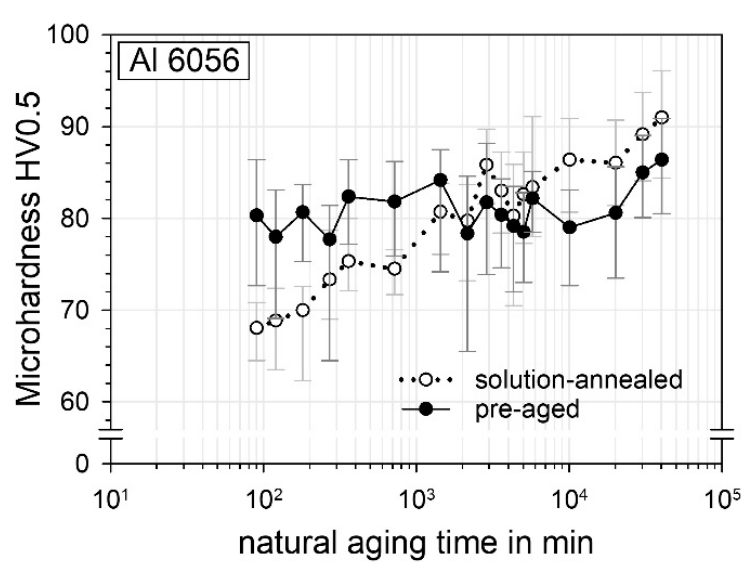

Figure 2. Microhardness of the 6056 aluminum alloy in solution-annealed and pre-aged conditions as a function of the natural aging time. Depicted are the mean, minimum and maximum values of the microhardness. The hardness of the solution-annealed sample increases continuously along with the increasing aging time, whereas for the pre-aged condition, the hardness remains almost constant during the first weeks.

The induced strain had only a minor influence on the hardness. An acceleration of the aging kinetics due to an increase in the induced strain was only noticeable for the solution-annealed condition extruded with $\varphi=1.2$. The peak hardness for this condition at approximately $152 \mathrm{HV} 0.1$ was already reached after $180 \mathrm{~min}$, which was the shortest peak-aging time for all of the extruded conditions.

\subsection{Tensile Properties}

In Figure 4, the ultimate tensile strengths as a function of the artificial aging time of the 6056 aluminum alloy in solution-annealed, pre-aged and naturally-aged conditions after linear extrusion with $\varphi=1.2$ are shown. With an increasing aging time, the strength of all three heat-treated conditions after extrusion significantly increased. The pre-aged condition exhibited the highest level of strength during the complete aging time, from $470 \mathrm{MPa}$ after $10 \mathrm{~min}$ to $532 \mathrm{MPa}$ after $360 \mathrm{~min}$. When compared with the naturally-aged condition, the strength of the pre-aged condition was in general approximately $4 \%$ higher, and was even as high as $10 \%$ when compared with the solution-annealed condition after $360 \mathrm{~min}$ artificial aging time.

\subsection{Microstructure}

On the example of the naturally aged condition, the microstructure parallel to the 238 processing direction and the differences in the grain aspect ratios respectively grain elon-239 gation dependent on the induced strain are shown in the optical micrographs in Figure 5. Linear extrusion primarily led to a change in the aspect ratios of the grains, while the grain elongation was increased with higher strains. No localized deformation was visible at $\varphi=1.2$, which corresponds to a relatively high induced strain. It has been shown previously that these strains can lead to localized deformation through the formation of shear bands in 6000 series aluminum alloys [25], which is clearly visible in optical micrographs and would influence the results of further investigations by a heterogeneous microstructures. The grains and grain boundaries of the undeformed aluminum wire were clearly noticeable (Figure 5a). As a result of the linear extrusion, the microstructure exhibited elongated grains parallel to the extrusion direction (Figure $5 b, c$ ). For the higher induced strain of $\varphi=1.2$, this effect was more pronounced (Figure 5c). 


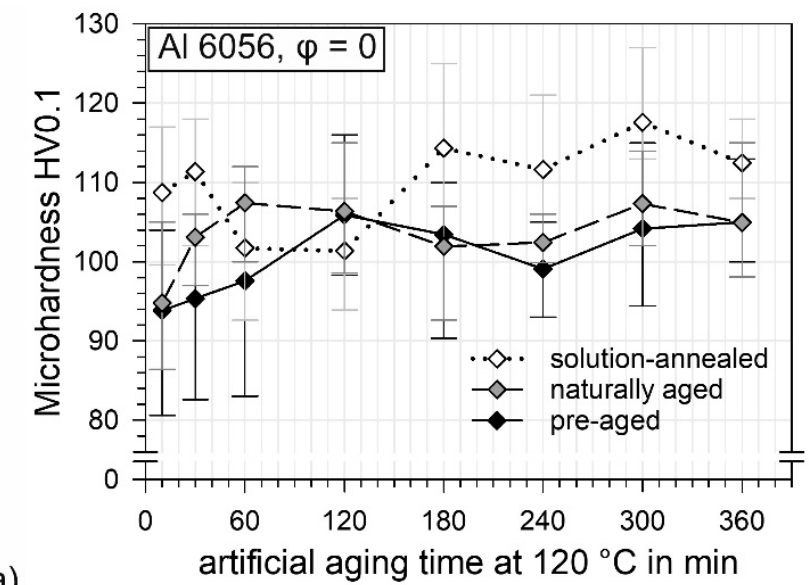

a) artificial aging time at $120^{\circ} \mathrm{C}$ in min

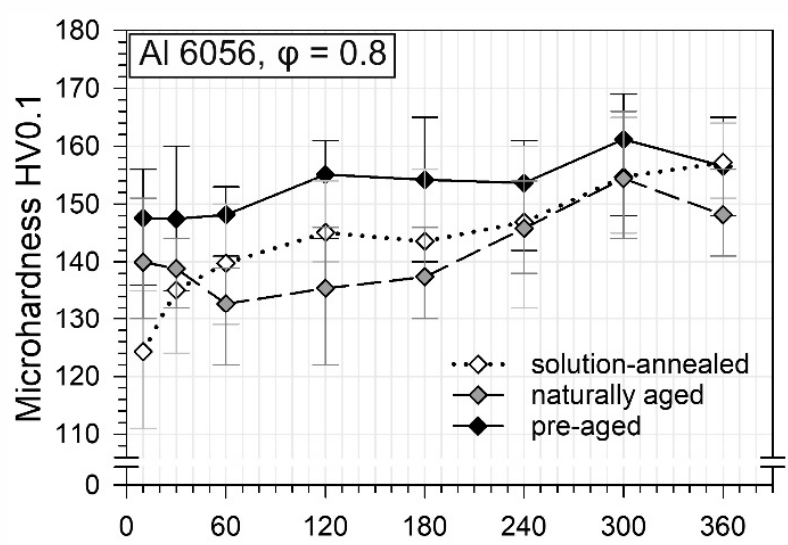

b) artificial aging time at $120^{\circ} \mathrm{C}$ in $\min$

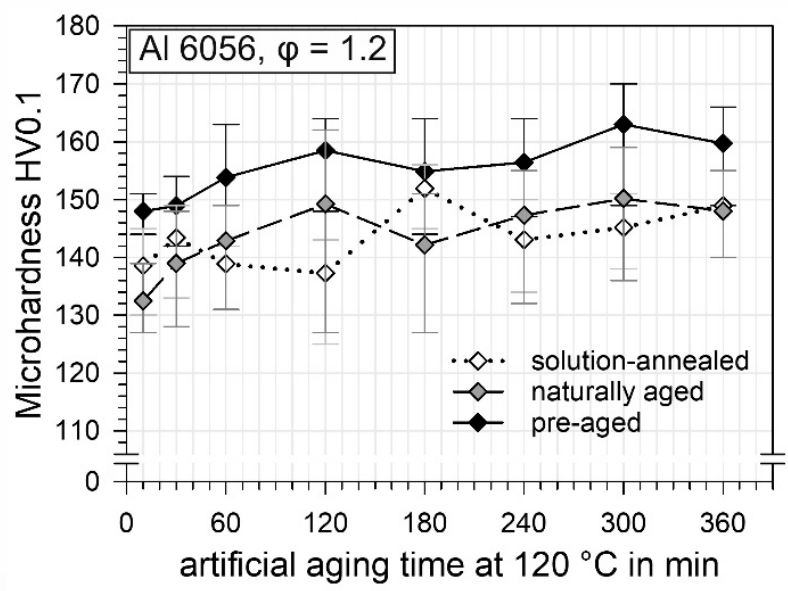

Figure 3. Microhardness of the 6056 aluminum alloy in solution-annealed, pre-aged and naturallyaged conditions as a function of the artificial aging time at $120{ }^{\circ} \mathrm{C}$ : (a) without previous plastic deformation and $(\mathbf{b}, \mathbf{c})$ after linear extrusion with induced strains of $(\mathbf{b}) \varphi=0.8$ and $(\mathbf{c}) \varphi=1.2$. Depicted are the mean, minimum and maximum values of each microhardness. Plastic deformation and pre-aging increase the hardness during artificial aging. 


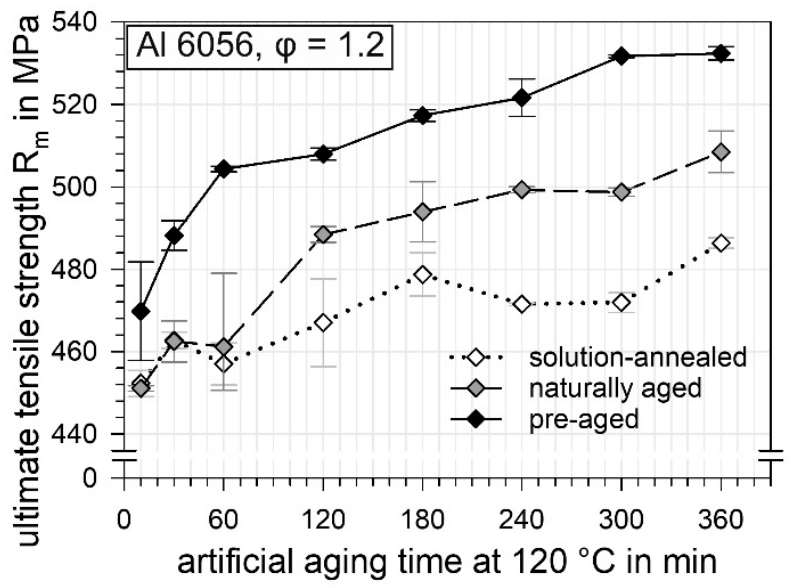

Figure 4. Ultimate tensile strengths of the 6056 aluminum alloy in solution-annealed, pre-aged and naturally-aged conditions as a function of the artificial aging time after linear extrusion with $\varphi=1$.2. Depicted here are the mean, minimum and maximum values of each tensile strength. The strength of the pre-aged condition is significantly higher when compared with the solution-annealed or naturally-aged conditions.

Al $6056, \Phi=0$

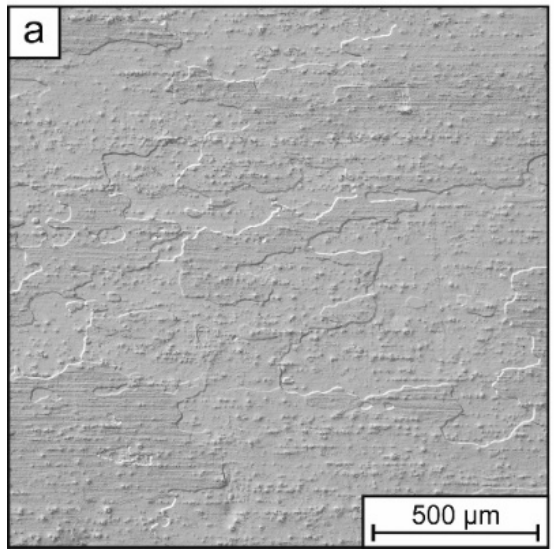

Al $6056, \Phi=0.8$

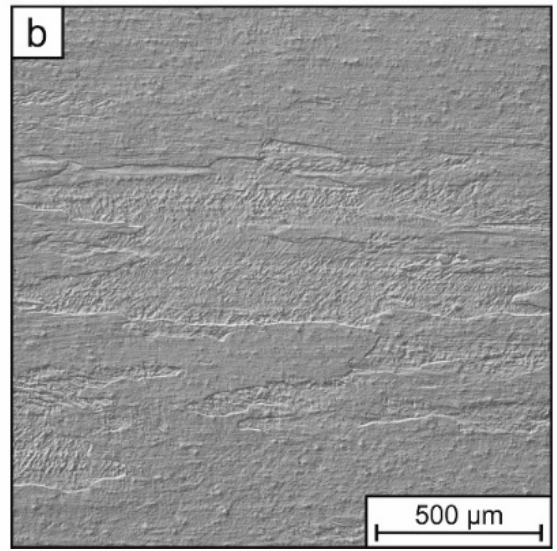

Al $6056, \Phi=1.2$

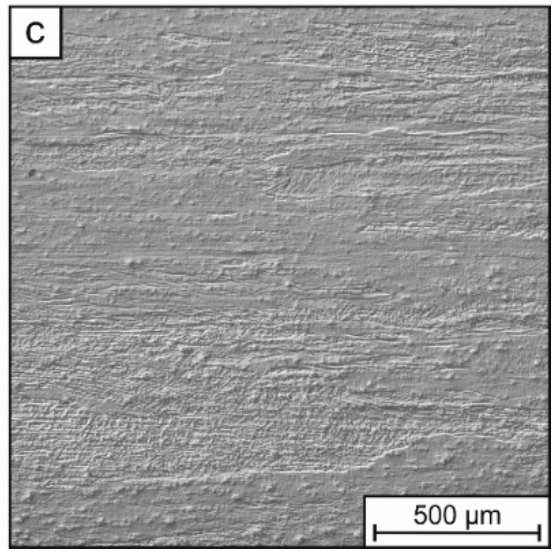

Figure 5. Optical micrographs of the 6056 aluminum alloy in the naturally-aged condition: (a) without previous plastic deformation and $(\mathbf{b}, \mathbf{c})$ after further linear extrusion with induced strains of $(\mathbf{b}) \varphi=0.8$ and $(\mathbf{c}) \varphi=1.2$. Because of the linear extrusion, the grains are highly elongated. This effect is more pronounced for the sample with the higher induced strain.

The micrographs in Figure 6 show the microstructures of the three initial heat-treated conditions and the same conditions following extrusion with $\varphi=1.2$ after 10 min of artificial aging at $120^{\circ} \mathrm{C}$. This short artificial aging time was chosen for the TEM analysis in order to investigate the potential microstructural differences between the initial heat-treatment conditions. All of the investigated conditions exhibited a high dislocation density due to the induced strain from the linear extrusion. Furthermore, regardless of the initial heat-treatment conditions, initial recovery due to artificial aging along with the formation of dislocation cells was noticeable (Figure 6). The solution-annealed condition exhibited a higher dislocation density when compared with the pre-aged and naturally-aged materials. However, the initial formation of dislocation cells was more pronounced for the pre-aged material. For the present large, globular intermetallic phases, which were most likely not dissolved during solid-solution treatment, high Mn and Si contents were detected by element analysis (Figure 6b,d,f). Regardless of the initial heat-treatment condition, because of the induced strain and the high dislocation density, fine precipitates, which formed during 10 min of artificial aging, could not be detected, as the high dislocation density and the strong contrast of the dislocations covered them up. 
Al 6056 solid-solution treated, $\Phi=1.2 \quad$ Al 6056 naturally aged, $\Phi=1.2$
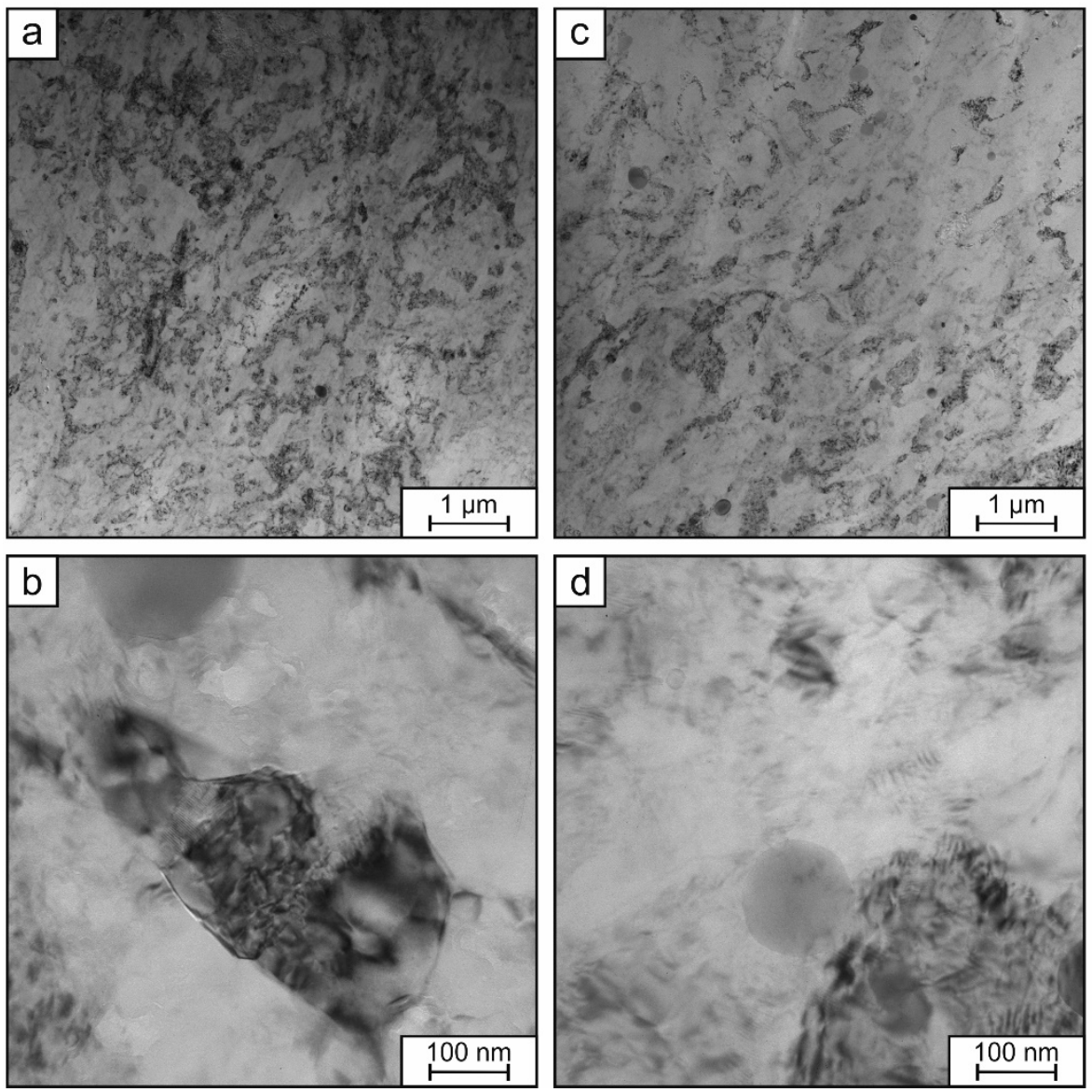

Al 6056 pre-aged, $\Phi=1.2$
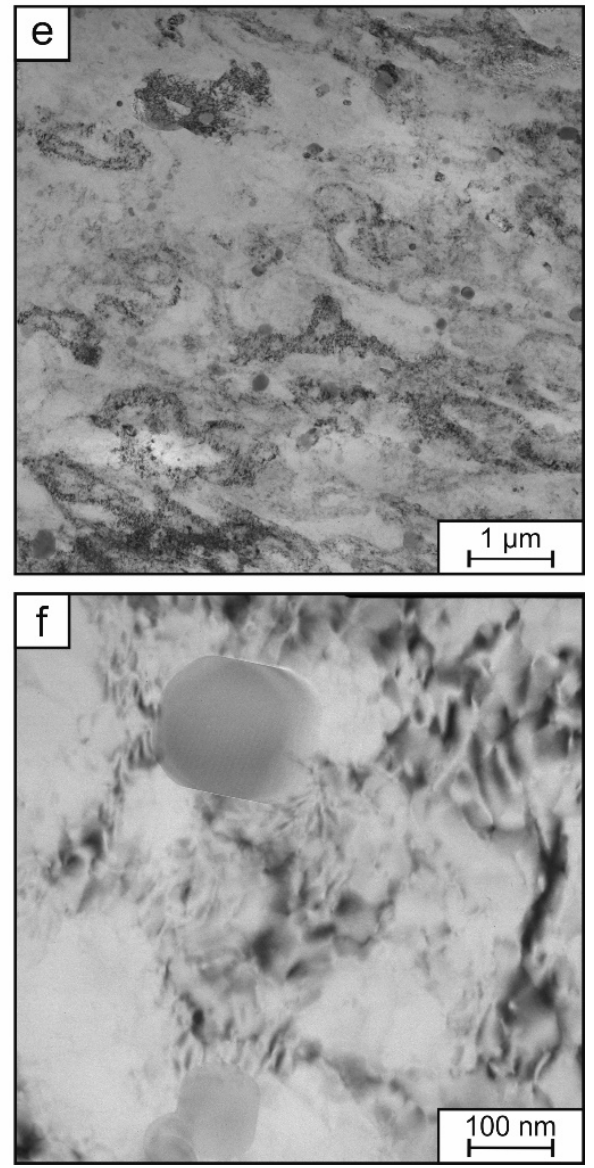

Figure 6. TEM micrographs of the 6056 aluminum alloy in $(\mathbf{a}, \mathbf{b})$ solid-solution treated, $(\mathbf{c}, \mathbf{d})$ naturally-aged and $(\mathbf{e}, \mathbf{f})$ preaged condition after linear extrusion with an induced strain of $\varphi=1.2$ and subsequent artificial aging at $120{ }^{\circ} \mathrm{C}$ for $10 \mathrm{~min}$. Regardless of the initial heat treatment, all conditions exhibit a high dislocation density along with the beginning arrangement in dislocation cells.

\section{Discussion}

\subsection{Effect of Pre-Aging}

The initial heat treatment has a significant influence on the precipitation kinetics and the aging behavior of the 6056 aluminum alloy. Natural aging after solid-solution treatment leads to the aggregation of separate $\mathrm{Mg}$ and $\mathrm{Si}$ clusters and the formation of Mg-Si co-clusters $[6,10,21,26,27]$. The nucleation of these low-temperature clusters results in an almost linear increase in hardness [28]. Based on the results of the DSC measurements, the formation of the Mg-Si co-clusters is suppressed through pre-aging, and GP zones are formed instead $[5,11,29]$. This process is controlled significantly by diffusion and the concentration of mobile quenched-in vacancies $[6,13,30,31]$. The presence of these highertemperature clusters explains the increased room temperature stability and, therefore, the hardness remaining almost constant within the first weeks [12,28]. The higher initial hardness of the pre-aged condition when compared to the solution-annealed condition is in good accordance with other studies [12,14,32]. With higher pre-aging temperatures, the initial hardness increases and, furthermore, the period of time during which the hardness remains constant during natural aging is extended $[11,12,32,33]$.

\subsection{Artificial Aging Behavior after Linear Extrusion}

The artificial aging behavior and the achieved hardness are primarily determined by the initial heat-treatment condition and the strain induced by linear extrusion. In 
accordance with the results for the non-extruded material, the solution-annealed condition exhibits a higher hardening rate and major hardness due to the rapid formation of the strengthening phase $\beta^{\prime \prime}[10,24,34]$. In contrast, the nucleation and growth of this phase is reduced for the naturally-aged and pre-aged conditions [24,35].

Additionally, the hardening response is slower $[10,36]$, which is in accordance with the results. Natural aging prior to artificial aging leads to a strongly reduced amount of mobile quenched-in vacancies and, therefore, to a decelerated hardening response $[6,10]$. $\mathrm{Zi}$ et al. [32] suggest that after pre-aging, the vacancies are in the thermal equilibrium state, which diminishes the hardening response. However, the artificial aging temperature has a significant influence on the formation rate and the density of $\beta^{\prime \prime}$, and the nucleation of this strengthening phase is accelerated by higher temperatures [10,37]. As the artificial aging temperature used here is significantly lower when compared with industrial standards, we assume that the reduced hardening response of the pre-aged condition when compared with the solution-annealed condition is as a result of the chosen temperatures. Additionally, we propose that the quite similar hardening responses of the naturally-aged and pre-aged conditions are a consequence thereof. In the DSC thermograms at $120^{\circ} \mathrm{C}$, the naturally-aged material exhibits a small exothermic peak, which indicates the formation of GP zones [22]. Although this peak is more pronounced for the pre-aged condition, it is shifted to higher temperatures. This might be the reason for the more rapid hardening of the naturally-aged condition when compared with the pre-aged material. In other studies [12,32] that report a higher hardness for the pre-aged condition when compared with the naturally-aged condition, higher artificial aging temperatures were chosen.

After extrusion, the achieved hardness during artificial aging is significantly increased for all initial heat-treatment conditions due to the induced strain and increased dislocation density $[7,16,18,38-41]$. However, the magnitude of the induced strain only marginally affects the achieved hardness and the hardening response when comparing the conditions extruded with $\varphi=0.8$ and $\varphi=1.2$, respectively.

In contrast to the non-extruded conditions, the artificial aging response of the pre-aged condition is large when compared with the naturally-aged condition, which is confirmed by other studies $[11,14,34,42]$. As the artificial aging temperature is quite low, this effect only occurs for the extruded conditions due to the induced strain and the resulting enhanced hardening response. Furthermore, the pre-aging temperature and time are significant factors for the artificial aging response and achieved hardness [11,32]. However, for the artificial aging behavior, the most important influence is exerted by the differently formed clusters during pre-aging and natural aging. The small Mg-Si co-clusters $[12,36,43]$ that are formed during natural aging are more stable because of their high binding energy $[11,36]$. Therefore, the direct transformation into $\beta^{\prime \prime}$ is impeded, as these clusters have to change their chemical and structural composition or must first dissolve [6,27,29,34-36]. As a result, the hardening response of the naturally-aged conditions during subsequent artificial aging is lower [11]. For the pre-aged condition, the larger-sized GP zones are chemically and structurally close to the $\beta^{\prime \prime}$ phase $[27,29,34-36]$. Therefore, these GP zones are more easily transformable and act as nucleation sites for the strengthening phase $\beta$ " $[14,26,27]$. Furthermore, the density of $\beta^{\prime \prime}$ is enhanced by pre-aging [27], as the number of quenched-in vacancies, which are necessary for $\beta^{\prime \prime}$ formation [6,34], are increased [31]. This explains the high hardness, which is also reflected in the ultimate tensile strength, of the pre-aged and extruded conditions during artificial aging, when compared with the corresponding naturally-aged solution-annealed conditions.

The solution-annealed condition extruded with $\varphi=1.2$ shows the most rapid hardening and the fastest achievement of peak hardness. The diffusion is supported by the high density of quenched-in vacancies after the solid-solution treatment [6], and the high dislocation density due to the cold plastic deformation $[7,15,16]$ further accelerates the precipitation kinetics of this condition. The numerous nucleation sites and the increased nucleation rate of $\beta^{\prime \prime}$ results in a rapid hardening response. Nevertheless, the overall hardness of the solution-annealed and extruded condition is minor when compared to the 
pre-aged and extruded condition, which is potentially a result of the induced strain and the low artificial aging temperatures. The strengthening effect, which was described in other studies [7,15,16,18,44], of the strategic application of cold plastic deformation in the solution-annealed condition followed by artificial aging majorly depends on the dislocation density. We assume the induced strain or the artificial aging temperature were too low to achieve a higher tensile strength and hardness when compared with the pre-aged or naturally-aged conditions.

\section{Summary}

The influence of the initial heat-treatment conditions on the artificial aging behavior after conventional linear extrusion at room temperature was investigated for the precipitation hardening of a 6056 aluminum alloy. A pre-aged condition was compared with solution-annealed and naturally-aged conditions. The influence of the pre-aging treatment on the natural aging behavior and on the hardening response during artificial aging after extrusion was systematically analyzed and compared with both of the other initial heat-treatment conditions. Solid-solution treatment and subsequent pre-aging at $80{ }^{\circ} \mathrm{C}$ for several hours was found to suppress the formation of $\mathrm{Mg}$-Si co-clusters, and, therefore, the room temperature stability was increased as the natural aging was inhibited. Furthermore, the artificial aging response after extrusion was significantly enhanced by pre-aging. The achieved hardness and ultimate tensile strength were high when compared with the naturally-aged and solution-annealed conditions that were extruded prior to artificial aging.

The results demonstrate that pre-aging is not only an effective strategy to prevent natural aging, but it can also decrease the accompanying aging response during the ofteninevitable interim storage periods between industrial production steps. Furthermore, the higher achievable mechanical properties after artificial aging following cold plastic deformation indicate a promising strategy for resource- and cost-efficient manufacturing. However, further research on the applicability of this thermomechanical treatment for complex industrial multistage forming processes, where the strain is often introduced heterogeneously, and its effect on the subsequent manufacturing steps is necessary.

Author Contributions: conceptualization, L.W. and K.H.; methodology, L.W., M.S., K.H. and R.J.H.; validation, L.W., M.S., K.H. and R.J.H.; formal analysis, L.W. and M.S.; investigation, L.W. and M.S.; resources, R.J.H. and T.L.; writing-original draft preparation, L.W.; writing-review and editing, M.S., K.H., R.J.H. and T.L.; visualization, L.W.; supervision, T.L.; project administration, K.H., R.J.H. and T.L.; funding acquisition, K.H., R.J.H. and T.L. All authors have read and agreed to the published version of the manuscript.

Funding: This work was supported by the German Research Foundation (Deutsche Forschungsgemeinschaft (DFG)) within the Collaborative Research Center SFB 692 “High-strength aluminum-based lightweight materials for safety components" (project number SFB692T7). The publication of this article was funded by the Chemnitz University of Technology in the funding program for open access publishing.

Institutional Review Board Statement: Not applicable.

Informed Consent Statement: Not applicable.

Conflicts of Interest: The authors declare no conflict of interest.

\section{References}

1. Andersen, S.J.; Zandbergen, H.W.; Jansen, J.; Træholt, C.; Tundal, U.; Reiso, O. The crystal structure of the $\beta^{\prime \prime}$ phase in Al-Mg-Si alloys. Acta Mater. 1998, 46, 3283-3298. [CrossRef]

2. Takeda, M.; Ohkubo, F.; Shirai, T.; Fukui, K. Stability of metastable phases and microstructures in the ageing process of Al-Mg-Si ternary alloys. J. Mater. Sci. 1998, 33, 2385-2390. [CrossRef]

3. Delmas, F.; Casanove, M.J.; Lours, P.; Couret, A.; Coujou, A. Quantitative TEM study of the precipitation microstructure in aluminium alloy $\mathrm{Al}(\mathrm{MgSiCu}) 6056$ T6. Mater. Sci. Eng. A 2004, 373, 80-89. [CrossRef] 
4. Chakrabarti, D.J.; Laughlin, D.E. Phase relations and precipitation in Al-Mg-Si alloys with Cu additions. Prog. Mater. Sci. 2004, 49, 389-410. [CrossRef]

5. Miao, W.F.; Laughlin, D.E. Effects of Cu content and preaging on precipitation characteristics in aluminum alloy 6022. Metall. Mater. Trans. A 2000, 31, 361-371. [CrossRef]

6. Pogatscher, S.; Antrekowitsch, H.; Leitner, H.; Ebner, T.; Uggowitzer, P.J. Mechanisms controlling the artificial aging of Al-Mg-Si Alloys. Acta Mater. 2011, 59, 3352-3363. [CrossRef]

7. Hockauf, K.; Meyer, L.W.; Hockauf, M.; Halle, T. Improvement of strength and ductility for a 6056 aluminum alloy achieved by a combination of equal-channel angular pressing and aging treatment. J. Mater. Sci. 2010, 45, 4754-4760. [CrossRef]

8. Zandbergen, M.W.; Cerezo, A.; Smith, G.D.W. Study of precipitation in Al-Mg-Si Alloys by atom probe tomography II. Influence of $\mathrm{Cu}$ additions. Acta Mater. 2015, 101, 149-158. [CrossRef]

9. Liu, S.; Li, K.; Lu, J.; Sha, G.; Wang, J.; Yang, M.; Ji, G.; Song, M.; Wang, J.; Du, Y. On the atomic model of Guinier-Preston zones in Al-Mg-Si-Cu alloys. J. Alloys Compd. 2018, 745, 644-650. [CrossRef]

10. Marioara, C.D.; Andersen, S.J.; Jansen, J.; Zandbergen, H.W. The influence of temperature and storage time at RT on nucleation of the $\beta$ " phase in a $6082 \mathrm{Al-Mg-Si} \mathrm{alloy.} \mathrm{Acta} \mathrm{Mater.} \mathrm{2003,} \mathrm{51,} \mathrm{789-796.} \mathrm{[CrossRef]}$

11. Saga, M.; Sasaki, Y.; Kikuchi, M.; Yan, Z.; Matsuo, M. Effect of Pre-Aging Temperature on the Behavior in the Early Stage of Aging at High Temperature for Al-Mg-Si Alloy. Mater. Sci. Forum 1996, 217-222, 821-826. [CrossRef]

12. Takaki, Y.; Aruga, Y.; Kozuka, M.; Sato, T. Effects of pre-aging and natural aging on bake hardening behavior in Al-Mg-Si alloys. Mater. Sci. Forum 2014, 794-796, 1026-1031. [CrossRef]

13. Serizawa, A.; Hirosawa, S.; Sato, T. Three-Dimensional Atom Probe Characterization of Nanoclusters Responsible for Multistep Aging Behavior of an Al-Mg-Si Alloy. Metall. Mater. Trans. A 2008, 39, 243-251. [CrossRef]

14. Matsuda, K.; Kawabata, T.; Uetani, Y.; Sato, T.; Kamio, A.; Ikeno, S. HRTEM observation of G.P. Zones and metastable phase in Al-Mg-Si alloys. Mater. Sci. Forum 2000, 331-337, 989-994. [CrossRef]

15. Kim, J.K.; Jeong, H.G.; Hong, S.I.; Kim, Y.S.; Kim, W.J. Effect of aging treatment on heavily deformed microstructure of a 6061 aluminum alloy after equal channel angular pressing. Scr. Mater. 2001, 45, 901-907. [CrossRef]

16. Hockauf, M.; Meyer, L.W.; Zillmann, B.; Hietschold, M.; Schulze, S.; Krüger, L. Simultaneous improvement of strength and ductility of Al-Mg-Si alloys by combining equal-channel angular extrusion with subsequent high-temperature short-time aging. Mater. Sci. Eng. A 2009, 503, 167-171. [CrossRef]

17. Kim, W.J.; Kim, J.K.; Park, T.Y.; Hong, S.I.; Kim, D.I.; Kim, Y.S.; Lee, J.D. Enhancement of strength and superplasticity in a 6061 Al alloy processed by equal-channel-angular-pressing. Metall. Mater. Trans. A 2002, 33, 3155-3164. [CrossRef]

18. Rezaei, M.R.; Toroghinejad, M.R.; Ashrafizadeh, F. Effects of ARB and ageing processes on mechanical properties and microstructure of 6061 aluminum alloy. J. Mater. Process. Technol. 2011, 211, 1184-1190. [CrossRef]

19. Milkereit, B.; Kessler, O.; Schick, C. Recording of continuous cooling precipitation diagrams of aluminium alloys. Thermochim. Acta 2009, 492, 73-78. [CrossRef]

20. Gallais, C.; Denquin, A.; Bréchet, Y.; Lapasset, G. Precipitation microstructures in an AA6056 aluminium alloy after friction stir welding: Characterisation and modelling. Mater. Sci. Eng. A 2008, 496, 77-89. [CrossRef]

21. Edwards, G.A.; Stiller, K.; Dunlop, G.L.; Couper, M.J. The precipitation sequence in Al-Mg-Si alloys. Acta Mater. 1998, 46, 3893-3904. [CrossRef]

22. Lloyd, D.J.; Evans, D.R.; Gupta, A.K. Precipitation reactions and the Differential Scanning Calorimetry response of AA6111 alloy. Can. Metall. Q. 2000, 39, 475-482. [CrossRef]

23. Buha, J.; Lumley, R.N.; Crosky, A.G.; Hono, K. Secondary precipitation in an Al-Mg-Si-Cu alloy. Acta Mater. 2007, 55, 3015-3024. [CrossRef]

24. Esmaeili, S.; Wang, X.; Lloyd, D.J.; Poole, W.J. On the precipitation-hardening behavior of the Al-Mg-Si-Cu alloy AA6111. Metall. Mater. Trans. A 2003, 34, 751-763.

25. Frint, P.; Wagner, M.F.-X. Strain partitioning by recurrent shear localization during equal-channel angular pressing of an AA6060 aluminum alloy. Acta Mater. 2019, 176, 306-317. [CrossRef]

26. Dutta, I.; Allen, S.M. A calorimetric study of precipitation in commercial aluminium alloy 6061. J. Mater. Sci. Lett. 1991, 10, 323-326. [CrossRef]

27. Murayama, M.; Hono, K. Pre-precipitate clusters and precipitation processes in Al-Mg-Si alloys. Acta Mater. 1999, 47, 1537-1548. [CrossRef]

28. Takata, K.; Takahashi, J.; Saga, M.; Ushioda, K.; Hibino, A.; Kikuchi, M. Effect of Two-Step Aging on Cluster Formation in Al-Mg-Si Alloys. Mater. Trans. 2014, 55, 885-891. [CrossRef]

29. Kim, J.H.; Kobayashi, E.; Sato, T. Effects of Cu Addition on Behavior of Nanoclusters during Multi-Step Aging in Al-Mg-Si Alloys. Mater. Trans. 2011, 52, 906-913. [CrossRef]

30. Pogatscher, S.; Antrekowitsch, H.; Leitner, H.; Pöschmann, D.; Zhang, Z.L.; Uggowitzer, P.J. Influence of interrupted quenching on artificial aging of Al-Mg-Si alloys. Acta Mater. 2012, 60, 4496-4505. [CrossRef]

31. Pogatscher, S.; Werinos, M.; Antrekowitsch, H.; Uggowitzer, P.J. The Role of Vacancies in the Aging of Al-Mg-Si Alloys. Mater. Sci. Forum 2014, 794-796, 1008-1013. [CrossRef]

32. Zi, Y.; Zeqin, L.; Leyvraz, D.; Banhart, J. Effect of pre-ageing on natural secondary ageing and paint bake hardening in Al-Mg-Si alloys. Materialia 2019, 7, 100413. [CrossRef] 
33. Yang, Z.; Liang, Z.; Leyvraz, D.; Banhart, J. Hardness data related to pre-ageing, natural secondary ageing, and paint bake hardening in Al-Mg-Si alloys. Data Br. 2019, 27, 104494. [CrossRef] [PubMed]

34. Yamada, K.; Sato, T.; Kamio, A. Effects of quenching conditions on two-step aging behavior of Al-Mg-Si alloys. Mater. Sci. Forum 2000, 331, 669-674. [CrossRef]

35. Engler, O.; Marioara, C.D.; Aruga, Y.; Kozuka, M.; Myhr, O.R. Effect of natural ageing or pre-ageing on the evolution of precipitate structure and strength during age hardening of Al-Mg-Si alloy AA 6016. Mater. Sci. Eng. A 2019, 759, 520-529. [CrossRef]

36. Zandbergen, M.W.; Xu, Q.; Cerezo, A.; Smith, G.D.W. Study of precipitation in Al-Mg-Si alloys by Atom Probe Tomography I. Microstructural changes as a function of ageing temperature. Acta Mater. 2015, 101, 136-148. [CrossRef]

37. Yu, W.; He, H.; Zhang, W.; Li, L.; Sun, C. Modulation of the natural aging effect on subsequent artificial aging in Al-Mg-Si aluminum alloys with alloying content $\sim 1 \mathrm{wt} \%$ through temperature tuning. J. Alloys Compd. 2020, 814, 152277. [CrossRef]

38. Papazian, J.M. A calorimetric study of precipitation in aluminum alloy 2219. Metall. Trans. A 1981, 12, 269-280. [CrossRef]

39. Zhao, Y.H.; Liao, X.Z.; Jin, Z.; Valiev, R.Z.; Zhu, Y.T. Microstructures and mechanical properties of ultrafine grained $7075 \mathrm{Al}$ alloy processed by ECAP and their evolutions during annealing. Acta Mater. 2004, 52, 4589-4599. [CrossRef]

40. Zuiko, I.; Gazizov, M.; Kaibyshev, R. Effect of cold plastic deformation on mechanical properties of aluminum alloy 2519 after ageing. Mater. Sci. Forum 2014, 794-796, 888-893. [CrossRef]

41. Ringer, S.P.; Muddle, B.C.; Polmear, I.J. Effects of cold work on precipitation in Al-Cu-Mg-(Ag) and Al-Cu-Li-(Mg-Ag) alloys . Metall. Mater. Trans. A 1995, 26, 1659-1671. [CrossRef]

42. Suzuki, H.; Kanno, M.; Itoh, G. A consideration of the two-step aging process in an Al-Mg-Si alloy. Aluminium 1981, 57, 628-629.

43. Liu, M.; Guo, Q.; Zhang, X.; Wüstenhagen, M.; Čížek, J.; Banhart, J. Clustering phenomena in quenched Al, Al-Mg, Al-Si and Al-Mg-Si alloys. Scr. Mater. 2020, 177, 203-207. [CrossRef]

44. Horita, Z.; Ohashi, K.; Fujita, T.; Kaneko, K.; Langdon, T.G. Achieving High Strength and High Ductility in Precipitation-Hardened Alloys. Adv. Mater. 2005, 17, 1599-1602. [CrossRef] 